\title{
Vitelliform macular degeneration associated with mitochondrial myopathy
}

\author{
Girish Modi, Jeannine M Heckman, David Saffer
}

\begin{abstract}
A patient with mitochondrial myopathy is described. Examination of his fundus revealed bilateral vitelliform degeneration of the maculae. This lesion is a focal abnormality of the retinal pigment epithelium and may be a manifestation of the underlying mitochondrial disease.
\end{abstract}

The mitochondrial myopathies (MM) or cytopathies or encephalomyopathies, as they are variably described, are a group of disorders with marked clinical and biochemical heterogeneity. The brain and muscle are the principal tissues that are affected, but involvement of haemopoietic, endocrine, cardiac, liver, and ocular tissues is well recognised.' Diagnosis of these conditions is based on the demonstration of morphological abnormalities of mitochondria on skeletal muscle biopsies; identification of biochemical defects, mainly along the respiratory chain; or as has been described recently by identification of abnormal or mutant mitochondrial (mt) DNA by means of restriction fragment length polymorphisms and DNA sequencing. ${ }^{1-3}$

The basis of the heterogeneity is explained in terms of the mitotic segregation hypothesis, whereby it is proposed that each cell contains a proportion of wild type and mutant mt DNA. ${ }^{46}$ When the relative proportion of mutant $\mathrm{mt}$ DNA is present at a critical threshold in a selected tissue, clinical disturbance of that tissue will result. ${ }^{3-6}$ This proportion of mutant mt DNA is transmitted maternally and is distributed by mitotic segregation at the time of zygote formation. ${ }^{3-6}$

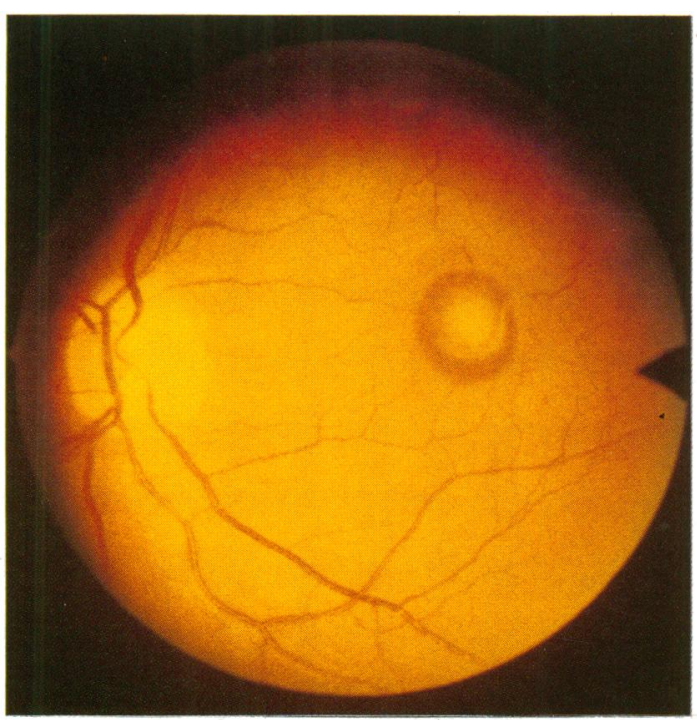

In this paper we describe the occurrence of vitelliform macular degeneration in a patient with infantile mitochondrial myopathy. The possible significance of this association is discussed.

\section{Case report}

A 20-year-old black male patient presented with symptoms of a multisystem disorder. He was of short stature (height $145 \mathrm{~cm}$ ) and had marked mental impairment. The essential findings were those of a proximal myopathy with a cardiopathy; ptosis without ophthalmoplegia; bilateral sensorineural deafness; distal symmetrical sensory neuropathy; and raised concentration of cerebrospinal fluid protein $(0.5 \mathrm{~g} / \mathrm{l})$. He had no dysmorphic features but showed evidence of delayed sexual maturation. Funduscopy revealed normal optic discs but striking vitelliform changes of the maculae (Fig 1). Biochemically the main abnormalities were those of a raised resting serum lactate $(2.8 \mathrm{mmol} / \mathrm{l}$; normal $=0 \cdot 16-1.8 \mathrm{mmol} / \mathrm{l})$ and a raised serum pyruvate $(83 \mathrm{mmol} / 1$, normal $=41-67 \mathrm{mmol} / \mathrm{l})$. A biopsy of the left biceps brachii showed that an estimated $10 \%$ of the fibres were 'ragged red' on the modified Gomori-trichrome stain (Fig 2a). Subsarcolemmal accumulations of mitochondria were noted on NADH-reductase stain. Cytochrome oxidase and phosphorylase activity was found to be normal with the appropriate stains for these enzymes. Electron microscopy revealed elongated and oval shaped mitochondria containing laminated paracrystalline inclusions (Fig 2b).

\section{Discussion}

Pigmentary retinopathy in association with mitochondrial myopathies (MM) is well described. ${ }^{17}$ Three patterns of retinopathy, namely, a 'salt and pepper' type, a retinitis pigmentosa type, and atrophy of the retinal pigment epithelium (RPE) have been described. ${ }^{7}$ Approximately $36 \%$ of patients with mitochondrial myopathies have involvement of the RPE, with the salt and pepper type being the commonest. ${ }^{7}$ The reasons for involvement of the RPE are not clear. The RPE contains large numbers of mitochondria, in keeping with its high energy state. ${ }^{7}$ Enlarged mitochondria and widespread loss or atrophy of the RPE in patients with MM have been described. ${ }^{7}$ However, the RPE mitochondria have not been studied in a functional manner in patients with $M M$, and biochemical abnormalities of muscle mitochondria described in patients with MM have not been reported in the RPE mitochondria.?

Vitelliform macular degeneration is recog-
Figure 1 Photograph of the patient's right fundus appearance diagnostic of the macula. The optic disc and vasculature are normal. No pigmentary retinopathy is present.

Neurology Unit,
Department of Medicine,
Baragwanath Hospital,
and the University of the
Witwatersrand,
Johannesburg, South
Africa
G Modi
J M Heckman
D Saffer
Correspondence to:
Dr G Modi.
Accepted for publication
30 May 1991


Figure 2 A: Gomoritrichrome stain of a section of the patient's muscle biopsy (biceps brachii) showing ragged red fibres with subsarcolemmal accumulation of mitochondria (arrows). $B$ Electron micrograph showing oval shaped mitochondria, with laminated paracrystalline inclusions (arrows). $(\times 42000$. $)$

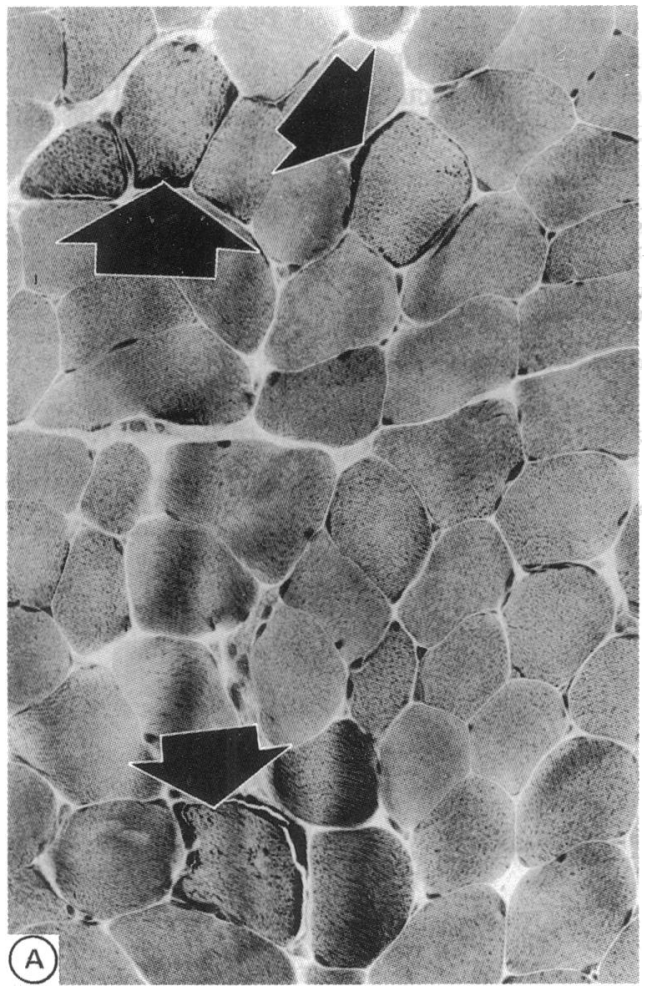

nised by its characteristic 'egg yolk' appearance. ${ }^{8}$ It is typically present in Best's disease, an autosomal dominant hereditary macular disease. ${ }^{89}$ In this disease the classical vitelline lesion, which is encountered infrequently, occurs focally in the region of the macula, but may occur multifocally and in extramacular sites. ${ }^{10}$ The lesions may be present uniocularly and occur asymmetrically. ${ }^{10}$ Diagnosis often requires the establishment of an autosomal dominant mode of inheritance as well as the demonstration of an abnormal electro-oculogram (EOG). ${ }^{8-10}$ The EOG is invariably abnormal in all affected members and carriers, and is abnormal in both eyes in cases where the lesion is uniocular. The abnormality in the EOG indicates that the disorder affects the RPE in a widespread manner and is not specifically a macular response.

Vitelline lesions may also occur in patients with a normal EOG and no evidence of a dominantly inherited maculopathy. These pseudovitelliform lesions occur in adults and have been associated with perifocal retinal capillary leakage, RPE and neurosensory detachments, or non-specific pigmentary changes. In these instances the vitelliform lesion is postulated to occur as a result of an acquired macular degeneration. ${ }^{10}$

The finding of vitelliform macular degeneration in a patient with $M M$ is therefore remarkable, and raises several possibilities regarding the reasons for the coexistence of these two uncommon diseases. The first is that this is a chance association of two rare disorders. The inheritance pattern of the $M M$ is maternal, ${ }^{3-5}$ whereas vitelliform macular degeneration, as it occurs in Best's disease, obeys nuclear Mendelian genetics. ${ }^{89}$ It is our contention, however, that vitelliform macular degeneration is a further atypical form of RPE abnormalities that occur as

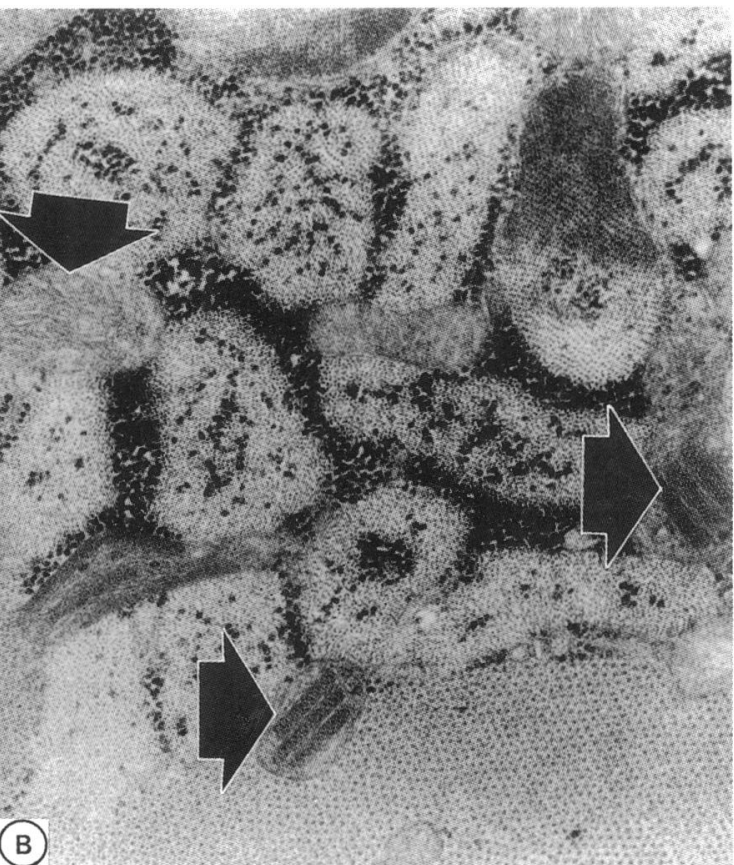

a consequence of $M M$ - that is, in addition to those already described by Mullie et al. ${ }^{7}$

In support of this contention is the observation of macular degeneration in a patient with mitochondrial encephalomyopathy and brain infarctions described by Kuriyama et al. " These authors described their patient as having a 'well demarcated white-yellow circular spot that resembled an egg-yolk'. While no photograph of the lesion is shown, this description is typical of vitelliform macular degeneration. We therefore consider that the association with MM is unlikely to be a chance finding. The degeneration would thus be due to widespread mitochondrial dysfunction in the RPE. This would be in keeping with the abnormal EOG found in this cisorder, which reflects the widespread involvement of the RPE. The reasons for the focal macular presentation are unclear but, in terms of the $M M$, one may speculate that differential distribution of mitochondria containing mutant mitochondrial DNA in the RPE would account for both focal macular and extramacular lesions. Further clinical and pathological analyses are important to determine the nature of this association.

With respect to Best's disease, the question that arises from the discussion above is whether or not it is a disorder of mitochondrial dysfunction. The autosomal dominant nature of the condition does not preclude it from being caused by mitochondrial disease. The concept of nuclear factors or genes influencing mitochondrial functions, with the resultant disease appearing to follow Mendelian genetics, has been proposed by several authors. ${ }^{1-5}$ Family pedigrees of patients with MM have been shown to follow dominant or recessive modes of inheritance..$^{1-5}$ In the case described here there was no clinical vitelliform macular degeneration in the patient's mother or step-sister. The grandmother has senile maculopathy, which can be difficult to distinguish from long standing vitelliform degeneration. ${ }^{9}$ We were unable to examine other family members or carry out EOG examina- 
tions. Kuriyama $e t a l^{11}$ also do not give details of family members in their case. Further investigations of established pedigrees of Best's macular dystrophy are therefore needed.

The authors thank Dr V Fabian, Department of Pathology, University of the Witwatersrand, Johannesburg, for her assistance with the histology and electron microscopic findings. Our thank also to Mrs B Pelser and Mrs J Gagu for typing the manuscript.

1 Petty RKH, Harding AE, Morgan-Hughes JA. The clinical features of mitochondrial myopathy. Brain 1986; 109: 915-38.

2 Harding AE. The mitochondrial genome - breaking the magic circle. N Engl F Med 1989; 320: 1341-3.

3 Holt IJ, Harding AE, Petty RKH, Morgan-Hughes JA. A new mitochondrial disease associated with mitochondrial DNA heteroplasmy. Am f Hum Genet 1990; 46: 428-33.

4 Rosing HS, Hopkins LC, Wallace DC, Epstein CM, Weidenheim K. Maternally inherited mitochondrial myopathy and myoclonic epilepsy. Ann Neurol 1985; 17: 228-37.
5 Di Mauro S, Bonilla E, Zeviani M, Nakagawa $M$, DeVivo C. Mitochondrial myopathies. Ann Neurol 1985; 17: 521-38.

6 Holt IJ, Harding AE, Morgan-Hughes JA. Deletions of mitochondrial DNA in patients with mitochondrial myopathies. Nature 1988; 331: 717-9.

7 Mullie MA, Harding AE, Petty RKH, et al. The retina manifestations of mitochondrial myopathy. Arch Ophthalmol 1985; 103: 1825-30.

8 Remsky H, Rix J, Klier KF. Dominant - autosomale Maculadegeneration (Best, Sorsby) mit zytischen und vitelliformen degeneration (Best, Sorsby) mit zytischen und vitelliformen 146: 473-97.

9 Cavender JC, Schwartz LJ, Spirey BE. Hereditary macular dystrophies. In: Duane TD, ed. Clinical ophthalmology. 2nd ed. Hagerstown: Harper and Row, 1978; 3: chapter 9: 1-16.

10 Noble KG. Hereditary macular dystrophies. In: Renie WA, ed. Goldberg's genetic and metabolic eye disease. 2nd ed. Little, Brown, Boston: 1986: 439-64.

11 Kuriyama M, Umezaki H, Fuduka Y, et al. Mitochondrial encephalomyopathy with lactate - pyrurate elevation and brain infarctions. Neurology 1984; 34: 72-7. 